\title{
Multigenic Control of Pod Shattering Resistance in Chinese Rapeseed Germplasm Revealed by Genome-Wide Association and Linkage Analyses
}

\author{
Jia Liu ${ }^{1+}$, Jun Wang ${ }^{1,2 \dagger}$, Hui Wang ${ }^{1}$, Wenxiang Wang ${ }^{1}$, Rijin Zhou ${ }^{1}$, Desheng Mei ${ }^{1}$, \\ Hongtao Cheng ${ }^{1}$, Juan Yang ${ }^{1}$, Harsh Raman ${ }^{3 *}$ and Qiong Hu ${ }^{1 *}$
}

${ }^{1}$ Key Laboratory of Biology and Genetic Improvement of Oil Crops, Ministry of Agriculture, Oil Crops Research Institute of the Chinese Academy of Agricultural Sciences, Wuhan, China, ${ }^{2}$ Graduate School of Chinese Academy of Agricultural Sciences, Beijing, China, ${ }^{3}$ Graham Centre for Agricultural Innovation (an Alliance between NSW Department of Primary Industries and Charles Sturt University), Wagga Wagga Agricultural Institute, Wagga Wagga, NSW, Australia

OPEN ACCESS

Edited by:

Joshua L. Heazlewood,

University of Melbourne, Australia

Reviewed by:

Elisa Bellucci,

Marche Polytechnic University, Italy

Marie Bruser,

John Innes Centre, UK

*Correspondence:

Harsh Raman

harsh.raman@dpi.nsw.gov.au

Qiong Hu

huqiong01@caas.cn

${ }^{\dagger}$ These authors have contributed equally to this work.

Specialty section

This article was submitted to Crop Science and Horticulture,

a section of the journal

Frontiers in Plant Science

Received: 29 January 2016 Accepted: 06 July 2016 Published: 21 July 2016

Citation:

Liu J, Wang J, Wang H, Wang W,

Zhou $R$, Mei $D$, Cheng $H$, Yang J, Raman H and Hu Q (2016) Multigenic Control of Pod Shattering Resistance

in Chinese Rapeseed Germplasm

Revealed by Genome-Wide

Association and Linkage Analyses.

Front. Plant Sci. 7:1058

doi: 10.3389/fp/s.2016.01058
The majority of rapeseed cultivars shatter seeds upon maturity especially under hot-dry and windy conditions, reducing yield and gross margin return to growers. Here, we identified quantitative trait loci (QTL) for resistance to pod shatter in an unstructured diverse panel of 143 rapeseed accessions, and two structured populations derived from bi-parental doubled haploid $(\mathrm{DH})$ and inter-mated $\left(\mathrm{IF}_{2}\right)$ crosses derived from $\mathrm{R} 1$ (resistant to pod shattering) and R2 (prone to pod shattering) accessions. Genome-wide association analysis identified six significant QTL for resistance to pod shatter located on chromosomes A01, A06, A07, A09, C02, and C05. Two of the QTL, qSRI.A09 delimited with the SNP marker Bn-A09-p30171993 (A09) and qSRI.A06 delimited with the SNP marker Bn-A06-p115948 (A06) could be repeatedly detected across environments in a diversity panel, $\mathrm{DH}$ and $\mathrm{IF}_{2}$ populations, suggesting that at least two loci on chromosomes A06 and A09 were the main contributors to pod shatter resistance in Chinese germplasm. Significant SNP markers identified in this study especially those that appeared repeatedly across environments provide a cost-effective and an efficient method for introgression and pyramiding of favorable alleles for pod shatter resistance via marker-assisted selection in rapeseed improvement programs.

Keywords: rapeseed, pod shatter resistance, genetic linkage mapping, genome-wide association, design breeding

\section{INTRODUCTION}

Rapeseed (Brassica napus L., $2 \mathrm{n}=4 \times=38$, genome AACC) is the third largest oilseed crop produced in the world after oil palm and soybean (USDA FAS, 2015) ${ }^{1}$. In nature, many plant species including rapeseed dehisce seeds easily upon maturity for dispersal and survival in subsequent generations. However, this phenomenon is one of the major bottlenecks in rapeseed production on a commercial scale. The yield loss due to seed shatter usually accounts for about $5-10 \%$ of total production; and under relatively harsh climatic conditions, it can reach up to 50\% (Kadkol et al., 1984; Price et al., 1996). Moreover, shattered seeds become "volunteers" in subsequent crops in the

\footnotetext{
${ }^{1}$ Oilseeds: World Markets and Trade|USDA FAS. Fas.usda.gov. Retrieved 2015-08-25.
} 
rotation cycle, making crop management difficult and expensive (Morgan et al., 2000). Rapeseed is generally harvested by windrowing or swathing. However, in recent years, farmers prefer to use combine harvesters, as this operation is less-labor intensive and cheaper compared to windrowing and manual harvesting. The latter is not an option for many western countries where rapeseed is often used as a broad-acre crop and harvested under very hot and dry conditions. Therefore, developing pod shatter resistant varieties suitable for combine harvesting has become one of the main breeding objectives of rapeseed improvement programs.

A limited genetic variation exists for pod shatter resistance in natural germplasm of rapeseed (Morgan et al., 1998; Wen et al., 2008). For example, Wen et al. (2008) evaluated 229 genotypes of rapeseed and identified only two genotypes having moderate levels of resistance to pod shatter. However, genetic variation for higher levels of resistance to pod shatter is present in other close relatives of rapeseed, such as Brassica rapa, Brassica juncea, and Brassica carinata (Kadkol et al., 1984; Mongkolporn et al., 2003; Raman et al., 2014). These related species have been utilized to improve pod shatter resistance in rapeseed via interspecific hybridization (Liu, 1994; Wei et al., 2010; Raman et al., 2014).

To gain insight into the genetic basis underlying quantitative variation in traits of agricultural significance such as pod shatter resistance and to enhance predictive selection efficiency in plant breeding programs, genetic mapping has become an important tool (Mauricio, 2001). Recent developments in nextgeneration sequencing technology, discovery of high throughput marker systems such as high density SNP markers (Trick et al., 2009; Bancroft et al., 2011), genotyping-by-sequencing (Raman et al., 2014; Bayer et al., 2015) and sequence capture (Schiessl et al., 2014), availability of chromosome based sequence of $B$. rapa, B. oleracea, and B. napus genomes (Wang et al., 2011; Chalhoub et al., 2014; Liu et al., 2014; Parkin et al., 2014) and bioinformatics, have enabled improving genomic selection of desirable alleles through marker-assisted selection in rapeseed. Multigenic inheritance for pod shatter resistance has been reported in B. rapa, and B. napus (Kadkol et al., 1986; Hossain et al., 2011; Wen et al., 2013). During the last 5 years, up to 10 QTL associated with resistance to pod shatter have been identified in both genetic mapping populations derived from doubled haploid (DH) lines (Hu et al., 2012; Wen et al., 2013; Raman et al., 2014) and a diversity panel of rapeseed accessions, originated mainly from Australia (Raman et al., 2014). Genetic loci associated with pod shatter resistance has also been mapped in B. rapa using RAPD markers (Mongkolporn et al., 2003), and soybean (Gao and Zhu, 2013). Several genes such as IND, ALC, SHP1, SHP2, and FUL and their complex regulatory network involved in pod dehiscence have been identified in Arabidopsis, rice and soybean (Ferrándiz et al., 2000; Liljegren et al., 2000; Rajani and Sundaresan, 2001; Konishi et al., 2006; Lewis et al., 2006; Li et al., 2006; Østergaard, 2009; Zhou et al., 2012; Dong et al., 2014; Funatsuki et al., 2014; Yoon et al., 2014).

In this study, we performed a genome wide association study (GWAS) in a diversity panel of 143 accessions and classical QTL analyses utilizing a $\mathrm{DH}$ population and inter-mated $\mathrm{F}_{2}$ $\left(\mathrm{IF}_{2}\right)$ population derived from R1 (resistant to pod shatter) and
R2 (prone to pod shatter) rapeseed advanced breeding lines of Chinese origin to identify loci involved in pod shatter resistance. The publicly available $60 \mathrm{~K}$ Brassica Infinium ${ }^{\circledR}$ SNP array was utilized to genotype mapping populations. We uncovered that pod shatter resistance is controlled by multiple loci having both major and minor allelic effects. Identification of loci via GWAS and classical QTL analyses, and SNP marker significantly associated with pod shatter resistance may facilitate a costeffective marker assisted selection of favorable alleles in rapeseed breeding programs.

\section{MATERIALS AND METHODS}

\section{Association Mapping Population}

A total of 143 diverse rapeseed accessions including 6 elite winter types, 124 semi-winter types, and 13 spring types were used for GWAS (Supplementary Table 1). Based on their origins, 112 accessions originated from China, 24 from Oceania, 5 from Europe, 1 from North America, and 1 from India. This GWAS panel also included parental lines; R1 and R2 utilized for the development of $\mathrm{DH}$ and $\mathrm{IF}_{2}$ populations investigated in this study. The seeds of all accessions were procured from the National Mid-term Genebank for Oil Crops, Wuhan, China, and then multiplied at the Oil Crops Research Institute of the Chinese Academy of Agricultural Sciences (OCRI-CAAS), Wuhan, China. All accessions were planted in a field following a randomized complete block design with 2 replications in 3 consecutive years $(2011,2012$, and 2013) at Yangluo Research Station (248 310S; 338 00E) in Hubei, China. Seeds were sown at normal agronomic density in plots of $2 \times 1 \mathrm{~m}$. Each plot contained three rows; each row with 18 plants. Field management followed the standard agricultural practice.

\section{DH Genetic Mapping Population}

A mapping population, designated as $\mathrm{RR}$, comprising $96 \mathrm{DH}$ lines was developed from an $\mathrm{F}_{1}$ plant derived from the cross of R1 (maternal parent) and R2 (paternal parent). The R1 and R2 were elite semi-winter breeding lines developed by OCRI-CAAS. $\mathrm{R} 1$ is a highly resistant advanced breeding line to pod shatter (Liu J. et al., 2013) whereas R2 is a highly prone to pod shattering line under field conditions; both lines are paternal lines of two high yielding commercial hybrid cultivar in China. The RR-DH population was grown in consecutive 2 years, i.e., 2013 and 2014 under winter-cropped environments at Yangluo Research Station and phenotyped for pod shatter resistance.

\section{Construction of Immortalized $\mathbf{F}_{\mathbf{2}}\left(\mathbf{I F}_{\mathbf{2}}\right)$ Validation Population}

In order to verify the genetic associations between SNP markers and pod shatter resistance identified in a RR-DH population and to understand additive interaction among loci, all $\mathrm{DH}$ lines were intercrossed following a random permutation design (Hua et al., 2002) for constructing an immortalized $F_{2}\left(I_{2}\right)$ population. The random permutation was repeated three times. In each permutation, the $96 \mathrm{DHs}$ were randomly divided into two groups, and the 48 lines in each group were paired up at random to a counterpart in the other group by taking one line from each 
group for one cross at a time and taking one from the rest lines for the next cross to ensure that each $\mathrm{DH}$ line was used only once in each round of permutation. Pairs with the same two parental lines from the three repeated permutation were manually corrected to eliminate identical pairings. In theory, 48 $\mathrm{IF}_{2}$ crosses should be produced from each round and in total 144 crosses could be obtained from the three repeats. However, some combinations failed to obtain seeds due to an asynchronous flowering of the parental DH lines, resulting in a total of $124 \mathrm{IF}_{2}$ derivatives. All parental DH lines and their hybrid derivatives $\left(\mathrm{F}_{1}\right)$ were planted in a randomized complete block design in Yangluo Experimental Station in 2013 winter season. Seeds were sown at normal agronomic density in plots $(2 \times 1 \mathrm{~m} /$ plot $)$. Each plot contained three rows with 18 plants in each row. Field management followed the standard agricultural practice.

\section{Assessment for Resistance to Pod Shattering}

At physiological maturity, 10 plants from the middle of the plots were harvested to evaluate their resistance to pod shatter. Ten pods from each plant were taken from the main inflorescence and then bulked to make a composite sample for measuring pod shatter resistance index (PSRI) using a modified random impact test (RIT; Peng et al., 2013). Samples of mature pods were first oven dried at $45^{\circ} \mathrm{C}$ for $8 \mathrm{~h}$ and then subjected to shaking at $300 \mathrm{rpm}$ in a drum with an inner diameter of 20 $\mathrm{cm}$ and a height of $12 \mathrm{~cm}$, together with ball bearings $(14 \mathrm{~mm}$ diameter). In this laboratory-based RIT procedure, the number of dispersed pods was recorded five times at 2 min intervals of standardized shaking. The PSRI was calculated as follows: PSRI $=1-\sum_{i=1}^{i=5} x i \times(6-i) / 100$, where $x_{i}$ is the number of ruptured pods at the $i$ th time $(1 \leq i \leq 5)$.

\section{SNP Genotyping}

Genomic DNA was isolated from pooled samples of young leaves from 5 plants of each genotype using a CTAB method (Saghai-Maroof et al., 1984). DNA content of each sample was measured using Nanodrop spectrometer (Model ND-2000). The DNA samples were genotyped with the Illumina Brassica $60 \mathrm{~K}$ Infinium ${ }^{\circledR}$ SNP array as per manufacture's protocol (Illumina Inc., San Diego, USA) by Emei Tongde Co. (Beijing). The SNP data were clustered and called using the Genome Studio genotyping software (Illumina). Among the three possible genotypes ( $\mathrm{AA}, \mathrm{AB}$, and $\mathrm{BB})$, genotypes with $\mathrm{AB}$ alleles was excluded, the remaining homozygous SNP markers were selected to carry out genetic analyses. Genotypic data were curated to remove those SNPs with AA or BB frequency equal to zero, call rates $\geq 0.8$ and minor allele frequency $<0.05$.

\section{Construction of a High Density SNP Genetic Map}

The software IciMapping V4.0 (Wang et al., 2014, http://www. isbreeding.net/software/?type=detail\&id=14) was used to "bin" redundant markers with exactly the same genotypes. Distortion in segregating SNP markers was checked using the $\chi^{2}$ test according to the expected segregation ratio $[\mathrm{AA}(1): \mathrm{BB}(1)]$ in $\mathrm{DH}$ population. Non-redundant SNP markers showing 1:1 segregation ratio were then used for construction of the genetic linkage map using the software JoinMap version 4.0 (Stam, 1993, https://www.kyazma.nl/index.php/mc.JoinMap), using a recombination frequency of $<0.25$ and minimum LOD score of 5. Recombination frequencies were converted using Kosambi's algorithm (Kosambi, 1944). Linkage groups were assigned to chromosomes A01 to A10 and C01 to C09 according to published genetic maps (Liu L. et al., 2013; Brown et al., 2014; Wang et al., 2015).

\section{In silico Mapping of SNP Markers}

In order to verify the chromosomal location of SNP markers and to compare their physical positions in relation to the known genes involved in pod shatter resistance in Arabidopsis thaliana and B. napus (www.tair.com, Girin et al., 2010; Hu et al., 2012; Raman et al., 2014; Dong and Wang, 2015), sequences of all associated SNPs and candidate genes were used to perform BlastN searches against the B. napus cv. Darmor genome sequence (Chalhoub et al., 2014). Only the top blast-hits with an $E$-value cut-off of $1 \mathrm{E}^{-15}$ were considered for genetic and comparative analyses. The closest known pod shatter resistance gene in relation to the physical position of SNP marker on the $B$. napus genome was assumed to be a "candidate" gene for pod shatter resistance in genetic mapping populations.

\section{Statistical Analysis and QTL Identification}

The PROC GLM procedure was used to estimate the variance components for individual traits/environments using SAS software version 8.1 (SAS Institute Inc., 1999). Genotype was considered a fixed effect, whereas environment was considered as random effects. The mean value of the trait was calculated and then used for genetic analysis.

The model of composite interval mapping (CIM) in the WinQTL cartographer version 2.5 (Wang et al., 2007) was used for QTL identification. Multiple linear regression was conducted using forward-backward stepwise and a probability model was set with 0.05 and window size at $10 \mathrm{cM}$. The LOD threshold was determined by 1000 permutation test (Churchill and Diverge, 1994) and a significant level of 0.01 were selected to determine whether there is any QTL for pod shatter resistance.

\section{Population Structure, Kinship, and GWA Analysis}

For GWAS, three data types are required: genotypic data, population structure within the GWA panel (population) and phenotypic trait information. After discarding SNP markers which were either monomorphic and/or had minor allele frequencies (MAFs) <0.05, a total of $66.1 \%(34,469 / 52,157)$ highquality polymorphic SNPs were selected for GWAS.

In order to infer the population structure of the GWAS panel, a subset of data of 2434 SNP markers which showed genome-wide coverage across all 19 chromosomes were used into the software package STRUCTURE version 2.3.4 (Pritchard et al., 2000). An admixture model was performed for five independent runs with a $K$-value, ranging from 1 to 10 , iterations of 100,000 times, burn-in period of 100,000 MCMC (Markov Chain Monte Carlo). 
The optimal $K$-value was determined according to the method of Evanno et al. (2005). The cluster membership coefficient matrices of replicate runs from STRUCTURE were integrated to get a Q matrix by the CLUMPP software (Jakobsson and Rosenberg, 2007). Accessions with the probability of membership $>0.7$ were assigned to corresponding clusters, and those $<0.7$ were assigned to a mixed group. Q matrices were used as covariates to calculate population structure with $\mathrm{K}$. The extent of LD for each chromosome was estimated using pairwise $r^{2}$ of all mapped SNPs using window of 500 .

With Best linear unbiased predictors (BLUPs) of calculated for all phenotypic environments (3 years, Table 1), we conducted a GWAS with 34,469 genome-wide SNPs using a univariate unified mixed linear model (Yu et al., 2006) that eliminated the need to recomputed variance components (i.e., population parameters previously determined, or P3D; Zhang et al., 2010). To control the effect of familial relatedness in GWAS, the kinship matrix based on coancestry (Loiselle et al., 1995) was estimated using 34,469 genome-wide SNPs. A likelihood-ratio-based $R^{2}$ statistic, denoted $R^{2}$ LR (Sun et al., 2010), was used to assess the amount of phenotypic variation explained by the model. The Benjamini and Hochberg (1995) procedure was used to control the multiple testing problem at false-discovery rates (FDRs) of 5 and $10 \%$. GWAS was performed by TASSEL 4.0 (Bradbury et al., 2007) using a mixed linear model (MLM) in which relative kinship matrix $(\mathrm{K})$ and population structure $(\mathrm{Q})$ were included as fixed and random effects, respectively. Significance of associations between traits and SNPs was set on threshold $P<2.90 \times 10^{-5}$ (i.e., $-\log _{10}(p)=4.5$ ). The threshold is 2.90 $\times 10^{-5}$ at a significant level of $1 \%$ after Bonferroni multiple test correction $(1 / 34,496)$. Furthermore, the false discovery rate (FDR at $P<0.05$ ) was applied to estimate the proportion of false positives among the significant associations (Dabney and Storey, 2004). The marker effect and the significant value generated in $\mathrm{R}$ package for each SNP were exported (http://cran.r-project. org). LD block analysis was performed as described previously, keeping the lead SNP within each LD block (Gabriel et al., 2002).

\section{Allelic Effects of Pod Shatter Accessions}

Based on pod shatter resistance indices, all 143 accessions were ranked and then investigated for allelic diversity at significant GWAS SNP loci. PSRI of R1 and R2 were 0.45 and 0.04 , respectively. Accessions having PSRI $\geq$ 0.28 were assumed to have superior alleles for pod shatter resistance.

\section{RESULT}

\section{Genetic Variation for Pod Shatter Resistance in Biparental Populations}

Predicted means for PSRI of $\mathrm{DH}$ and $\mathrm{IF}_{2}$ populations showed a continuous distribution for pod shatter resistance irrespective of growing environments. Both parental lines differed significantly in pod shatter resistance across all phenotyping environments. R1, the resistant parent, had consistently higher PSRI (0.45) compared to the pod shatter prone parent, R2 (0.04; Figure 1).
The frequency distribution of PSRI deviated significantly from normality among $\mathrm{DH}$ and $\mathrm{IF}_{2}$ lines $(P<0.001)$. Among RR$\mathrm{DH}$ lines, a strong positive correlation $(r=0.60)$ of genotype performance for PSRI was observed across 2013 and 2014 environments (Figure 2), suggesting that phenotypic variation in PSRI is genetically controlled, consistent with high broad-sense heritability values (Table 1). Analysis of variance showed that the effects of genotype $(G)$, and genotype $\times$ environment $(G \times E)$ interaction on PSRI were significant (Table 1), suggesting that genetic mapping populations must be evaluated across multiple sites/years to ensure valid phenotypic assessment.

\section{Construction of a High-Density Genetic Bin Map for QTL Analysis}

Of the 52,157 SNP markers (60K Infinium array), only $16.4 \%$ (8540) were polymorphic between the parental lines, R1 and R2 of the RR-DH population. Of these, 7804 SNP markers showing 1:1 segregation ratio, as determined by the $\chi^{2}$ test $(P=0.05)$, were used for construction of a genetic linkage map and QTL analysis. A majority (99\%) of the polymorphic markers (7728/7804) were anchored to the 19 chromosomes of B. napus and mapped to 2046 distinct loci, with 1384 loci on A genome, and 662 loci on the $\mathrm{C}$ genome (Table 2, Figure 3). A total of 5682 SNP loci showed cosegregation and could be grouped into 900 discrete bins. A genetic linkage map of RR-DH population spanned 2217.2 cM of Kosambi map distance. The marker density of the 19 chromosomes ranged from 0.61 (A03) to 2.96 (C09), with an average of $1.08 \mathrm{cM}$. The chromosome A03 displayed the maximum marker density (738 markers representing 222 loci) and chromosome C09 had the least density (77 markers representing 24 loci). In particular, chromosomes C08 and C09 were shorter $(66.6-71 \mathrm{cM})$ than rest of the chromosomes (Table 2).

The SNP genotypes of $124 \mathrm{~F}_{1}$ hybrids were deduced from their corresponding $\mathrm{DH}$ parental lines to provide a bin map for the $\mathrm{IF}_{2}$ crosses (Figure 3). There were three genotypes in each bin: homozygous genotype from R1 $(M M)$, homozygous genotype from R2 $(\mathrm{mm})$, and heterozygous genotype $(\mathrm{Mm})$. The average proportion of three genotypes for each cross was 27.3, 29.2, and $43.5 \%$, respectively. Therefore, the composition of genotypes in $\mathrm{IF}_{2}$ was similar to that in an $\mathrm{F}_{2}$ population. This population could therefore be used to detect QTL with the same analytical method used for an $\mathrm{F}_{2}$ population.

\section{QTL Associated with Pod Shattering Resistance in a RR-DH Population}

In the RR-DH population, four significant QTL qSRI.A01a, qSRI.A06a, qSRI.A06b, and qSRI.A09 were detected for PSRI on chromosomes A01, A06, and A09 (Table 3). These QTL accounted for $5.66-16.91 \%$ of the phenotypic variation. The qSRI.A09 (LOD $=4.31-7.69$ ) accounted for the maximum phenotypic variation in pod shatter resistance (9.81-16.9\%). Two QTL, qSRI.A09 delimited with the SNP Bn-A09-p30171993 (A09) and qSRI.A06b delimited with the SNP marker BnA06-p115948 (A06) were repeatedly detected across both 
TABLE 1 | Genetic variation and broad-sense heritability in pod shatter resistance index (PSRI) among three populations.

\begin{tabular}{|c|c|c|c|c|c|c|c|c|}
\hline Population & $\begin{array}{c}\text { Phenotyping environment } \\
\text { (year) }\end{array}$ & PSRI (range) & PSRI (Mean \pm SD) & CV (\%) & Genotype (G) & Environment (E) & $\mathbf{G} \times \mathbf{E}$ & $\mathrm{H}^{2}(\%)$ \\
\hline \multirow[t]{2}{*}{$\mathrm{DH}$} & 2013 & $0.01-0.58$ & $0.14 \pm 0.12$ & 92.49 & $\star \star$ & 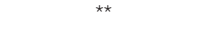 & $\star \star$ & 85.11 \\
\hline & 2014 & $0.03-0.99$ & $0.46 \pm 0.28$ & 61.48 & & & & \\
\hline $\mathrm{IF}_{2}$ & 2014 & $0.05-0.99$ & $0.50 \pm 0.27$ & 53.70 & $\star \star$ & & & \\
\hline \multirow[t]{3}{*}{ GWAS diversity set } & 2011 & $0.00-0.58$ & $0.09 \pm 0.11$ & 119.32 & $\star *$ & & & 92.11 \\
\hline & 2012 & $0.01-0.64$ & $0.15 \pm 0.14$ & 87.54 & & & & \\
\hline & 2013 & $0.00-0.71$ & $0.09 \pm 0.14$ & 154.04 & & & & \\
\hline
\end{tabular}

${ }^{\star *} P<0.01$ for the effect of genotype (G), environment (E), and genotype by environment interaction (G $\times$ E) on phenotypic variance estimated by two-way ANOVA. $\mathrm{CV}$, coefficient of variation; $\mathrm{H}^{2}$, broad sense heritability; $\mathrm{SD}$, Standard deviation.

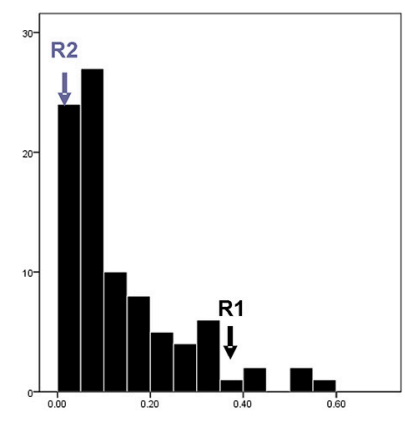

DH -2013

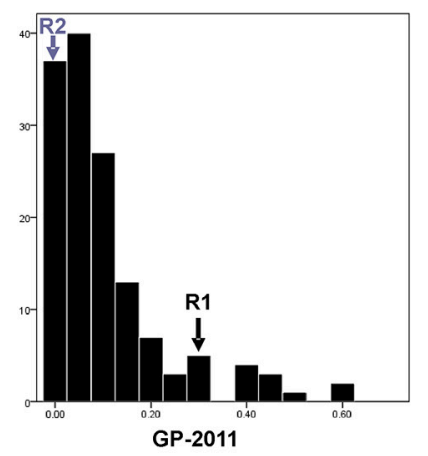

GP-2011

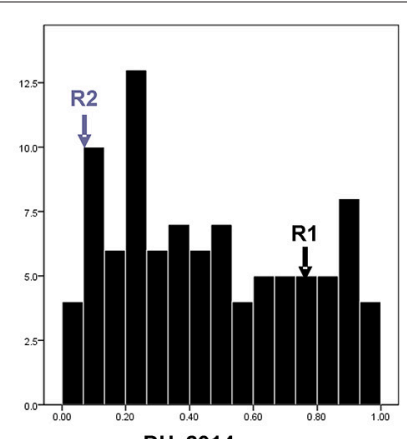

DH-2014

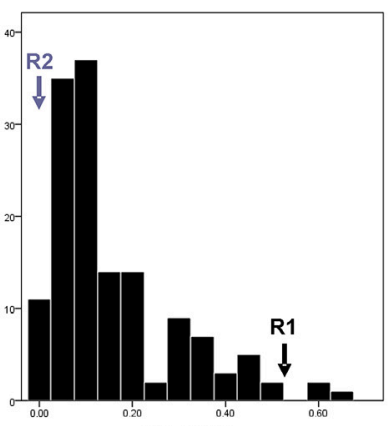

GP-2012

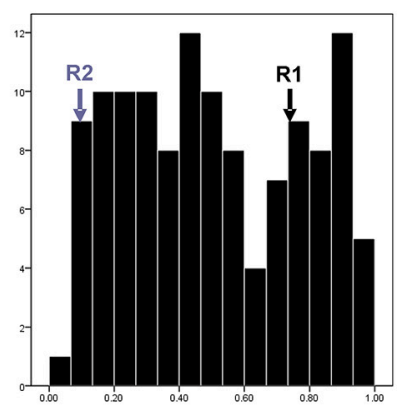

IF2 -2014

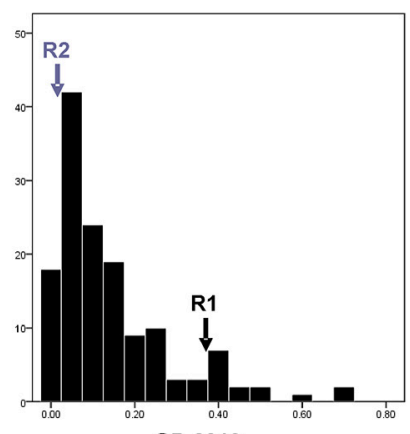

GP-2013

FIGURE 1 | Phenotypic distribution for individual pod shatter resistance index in DH population (R1 x R2) across 2 years (2013 and 2014$)$ and IF 2 population (2014), and GWAS panel (GP) across 3 years (2011, 2012, and 2013). Transgressive segregation was observed in the DH and IF 2 populations from all of the environments. Gray arrows are for R2 and black arrows are for R1. y axis represents Number of lines and accessions and $\mathrm{x}$ axis represents pod shatter resistance index measured by RIT (Random Impact Test) method.

environments in 2013 and 2014. It is possible that QTL $q S R I . A 06 a$ and $q S R I . A 06 b$ may be the same, as both were detected in close proximity of Bn-A06-p15913910/Bn-A06-p115948 markers, mapped within $250 \mathrm{~kb}$ on the physical map of $B$. napus genome (Table 3, Supplementary Table 4). The pod shatter resistant parent, R1 contributed favorable alleles for pod shatter resistance based on RTI at all QTL detected (Table 3), consistent with the high pod shatter resistance index of R1 compared to R2 (Figure 1).

\section{Verification of Loci Associated with Pod Shatter Resistance in $\mathbf{I F}_{\mathbf{2}}$ Population}

In order to verify the allelic effects of QTL revealed in a RR-DH population (Table 3), we performed an independent linkage analysis for association between SNP markers and genetic variation in pod shatter index evaluated in an $\mathrm{IF}_{2}$ population (Figure 1, Table 3). We identified four QTL, qSRI.A01b, qSRI.A03, qSRI.A06b, and qSRI.A09 for PSRI on chromosomes A01, A03, A06, and A09, respectively (Table 3). Two consistent and stable QTL qSRI.A06b and qSRI.A09, as identified in RR-DH population, were also detected in an $\mathrm{IF}_{2}$ population. The same set of markers, Bn-A06-p115948 (A06) and Bn-A09-p30171993 (A09) revealed significant phenotypic variation for pod shatter resistance (Table 3). Significant QTL, qSRI.A01b (A01) and qSRI.A03 (A03) were defined by the SNP markers Bn-A01p2365493 and Bn-scaff-22728-1-p75030, respectively (Table 3). These QTL accounted for up to $13.14 \%$ of phenotypic variation in PSRI. 

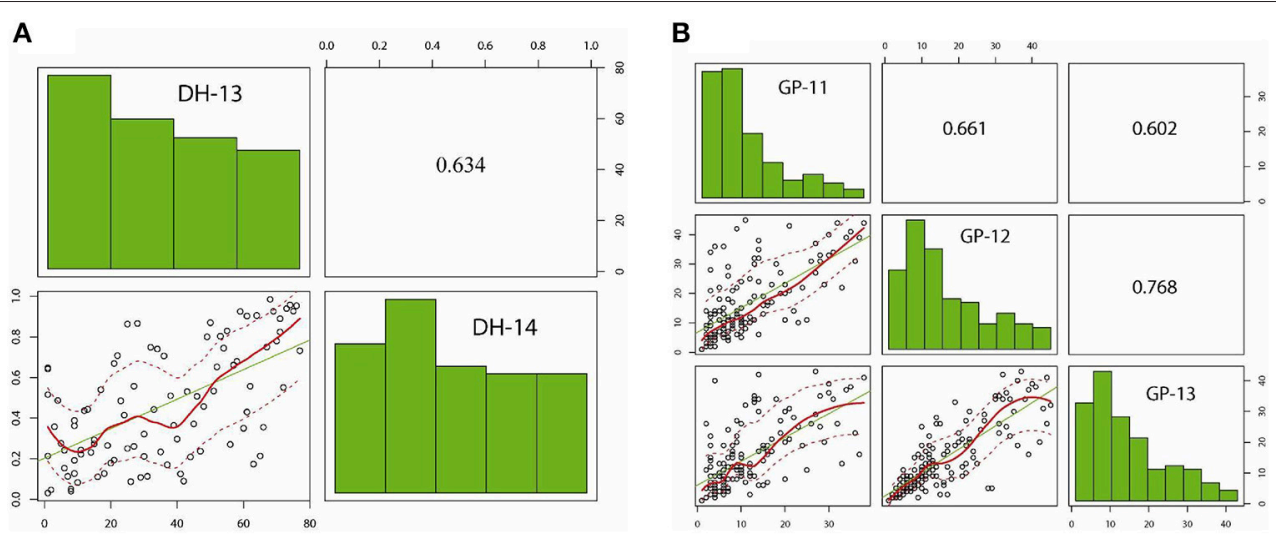

FIGURE 2 | Distribution of pod shatter resistance, as measured with the random impact test, among DH lines from the R1/R2 and GWAS diversity set. Pair-plots of EBLUPS from DH lines and GWAS diversity set showing correlations are presented. (A) R1/R2 population grown under two environments: experiment 1 (DH-13); experiment 2 (DH-14). (B) GWAS diversity set grown under three environments: GP-11, GP-12, and GP-13.

TABLE 2 | Features of the genetic linkage map of a DH population derived from R1 /R2 of B. napus*.

\begin{tabular}{|c|c|c|c|c|c|c|}
\hline Chromosome & $\begin{array}{c}\text { No. of polymorphic } \\
\text { markers }\end{array}$ & $\begin{array}{c}\text { No. of mapped } \\
\text { markers }\end{array}$ & $\begin{array}{l}\text { No. of mapped markers } \\
\text { in bin loci }\end{array}$ & No. of bin loci & Map length (cM) & $\begin{array}{l}\text { Average distance } \\
\text { between loci (cM) }\end{array}$ \\
\hline $\mathrm{A} 01$ & 329 & 233 & 145 & 49 & 95.9 & 0.66 \\
\hline A02 & 317 & 269 & 98 & 50 & 117.5 & 1.20 \\
\hline $\mathrm{A} 03$ & 738 & 612 & 222 & 96 & 136.5 & 0.61 \\
\hline $\mathrm{A} 04$ & 191 & 448 & 139 & 60 & 126.8 & 0.91 \\
\hline A05 & 615 & 498 & 199 & 84 & 125.1 & 0.63 \\
\hline A06 & 450 & 359 & 158 & 67 & 133.2 & 0.84 \\
\hline A07 & 483 & 417 & 122 & 56 & 98.8 & 0.81 \\
\hline $\mathrm{A} 08$ & 269 & 237 & 52 & 20 & 108.2 & 2.08 \\
\hline A09 & 632 & 546 & 147 & 61 & 135.1 & 0.92 \\
\hline A10 & 191 & 115 & 102 & 26 & 118.9 & 1.17 \\
\hline C01 & 405 & 361 & 81 & 37 & 147.9 & 1.83 \\
\hline $\mathrm{CO} 2$ & 891 & 852 & 94 & 55 & 104.4 & 1.11 \\
\hline $\mathrm{CO3}$ & 665 & 602 & 123 & 60 & 134.3 & 1.09 \\
\hline C04 & 574 & 526 & 106 & 58 & 163.4 & 1.54 \\
\hline $\mathrm{C05}$ & 147 & 116 & 56 & 25 & 123.8 & 2.21 \\
\hline $\mathrm{CO6}$ & 500 & 469 & 73 & 42 & 110.1 & 1.51 \\
\hline $\mathrm{CO7}$ & 794 & 769 & 39 & 14 & 99.7 & 2.56 \\
\hline $\mathrm{C08}$ & 272 & 239 & 66 & 33 & 66.6 & 1.01 \\
\hline C09 & 77 & 60 & 24 & 7 & 71.0 & 2.96 \\
\hline Subtotal for the A genome & 4215 & 3734 & 1384 & 569 & 1196.0 & 0.86 \\
\hline Subtotal for the $\mathrm{C}$ genome & 4325 & 3994 & 662 & 331 & 1021.2 & 1.54 \\
\hline Total $(A+C)$ & 8540 & 7728 & 2046 & 900 & 2217.2 & 1.08 \\
\hline
\end{tabular}

"Markers which showed co-segregation with each other were binned using the ICI mapping package (http://www.isbreeding.net/software/?type=detail\&id=14).

GWAS Analysis for Pod Shatter Resistance in a Diversity Panel

In order to identify loci associated with pod shatter resistance in a diverse panel of accessions, exploiting the historic recombination events, we conducted a GWAS using the $\mathrm{Q}+\mathrm{K}$ model accounting both for population structure as well as kinship relatedness (Bradbury et al., 2007). Based on a probability-of-membership (a measure of population structure) with threshold of $70 \%$, a diversity panel of 143 lines could be assigned to three groups (group I: 17 lines, group II: 99 lines, and group III: 27 lines representing a mixed group; Supplementary Table 1). In addition, cluster analysis was 


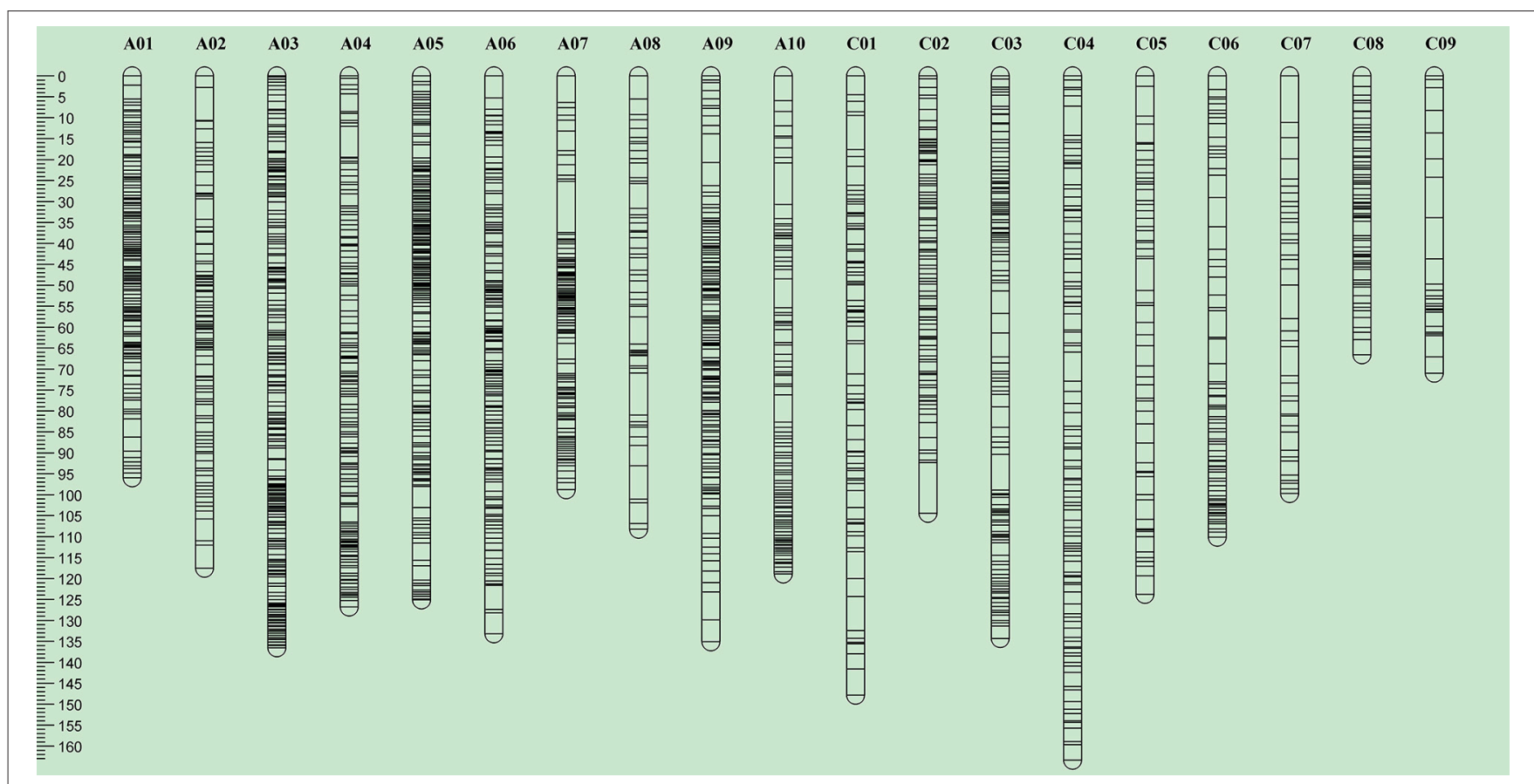

FIGURE 3 | Overview of genome-wide SNP density in the bin map of the RR-DH population derived from R1 (resistant to pod shatter) and R2 (prone to pod shatter) lines of $\boldsymbol{B}$. napus. The ordinate shows the genetic distance along each of the 19 linkage groups corresponding to the 19 B. napus chromosomes.

Scale in Kosambi centimorgans (cM) is on the left.

conducted; the Neighbor-Joining phylogenetic tree based on Nei's genetic distances displayed two clear clades (Supplementary Figure 1), reconfirming the presence of two groups (group I and II, Supplementary Table 1) estimated by STRUCTURE. Estimates of an average nucleotide diversity (also known as polymorphism information content or PIC) of 0.366 showed that the overall genetic variation in the germplasms studied here represents $\sim 62.9 \%$ of the rapeseed diversity (PIC $>0.35$; Supplementary Table 2). In order to test the robustness of population structure revealed by cluster analysis, we also used the $\Delta \mathrm{k}$ method (Evanno et al., 2005). The 143 accessions could be divided into two sub-populations (Supplementary Figure 2). The average relative kinship between any two lines was 0.0332 , or $\sim 57 \%$ of the pairwise kinship estimates were close to 0 , and $21 \%$ of the kinship estimates ranged from 0 to 0.05 (Supplementary Figure 3). The genome-wide LD decay of each chromosome for rapeseed germplasms is shown in Supplementary Figure 4.

GWAS detected a total of 38 SNPs that showed significant association (up to $P<2.90 \mathrm{E}^{-5}$ ) with pod shatter resistance across three environments (Table 3, Supplementary Table 3). After Bonferroni correction, we identified 6 genomic regions (QTL) on chromosomes A01, A06, A07, A09, C02, and C05 accounting for up to $45.9 \%$ cumulative phenotypic variance for pod shatter resistance in a GWAS panel (Table 3). Multiple environment analyses revealed that at least two QTL, qSRI.A06b delimited with the SNP marker Bn-A06-p115948 (A06) and qSRI.A09 delimited with the SNP Bn-A09-p30171993 (A09) could be repeatedly detected across populations $\left(\mathrm{DH}, \mathrm{IF}_{2}\right.$, and GWA panel) as shown in Table 3. Significant QTL associated with SNPs Bn-A07-p7392457 (A07), Bn-scaff_15712_6-p214229 (C02), and Bn-scaff_17869_1-p1058624 (C05) were not detected in both RR-DH/IF 2 genetic mapping populations.

\section{Physical Mapping of Significant QTL for Pod Shatter Resistance in Comparison to Previously Detected QTL and Candidate Genes}

In order to gain insights of genetic architecture of pod shatter resistance loci, we compared the physical positions of markers associated with QTL identified in this current and previously studies (Hu et al., 2012; Raman et al., 2014). The sequences of markers significantly associated with pod shatter resistance were subjected to BLAST against the physical reference genome of $B$. napus. The markers linked with pod shatter resistance loci on chromosome A09: NS380 and NS381 (Hu et al., 2012), DArTseq markers 3146978 and 3105723 (Raman et al., 2014) and Bn-A09-p30171993 (this study) were located within $\sim 400$ $\mathrm{kb}$ region of $B$. napus genome (Figure 4). This genomic region delimited from 30.84 to $31.98 \mathrm{Mb}$ of $B$. napus genome also contains QTL having major allelic effects for pod length and seed weight in rapeseed ( $\mathrm{Li}$ et al., 2014; Fu et al., 2015). A recent research showed that the AUXIN RESPONSE FACTOR 18 (ARF18) gene affecting seed weight and pod length is located within this region (Liu et al., 2015). These studies suggested that qSRI.A09 is a hotspot region for seed yield and pod traits such as pod shatter resistance and pod length in rapeseed. The major QTL genomic regions on A09 (Table 3) were consistent as 


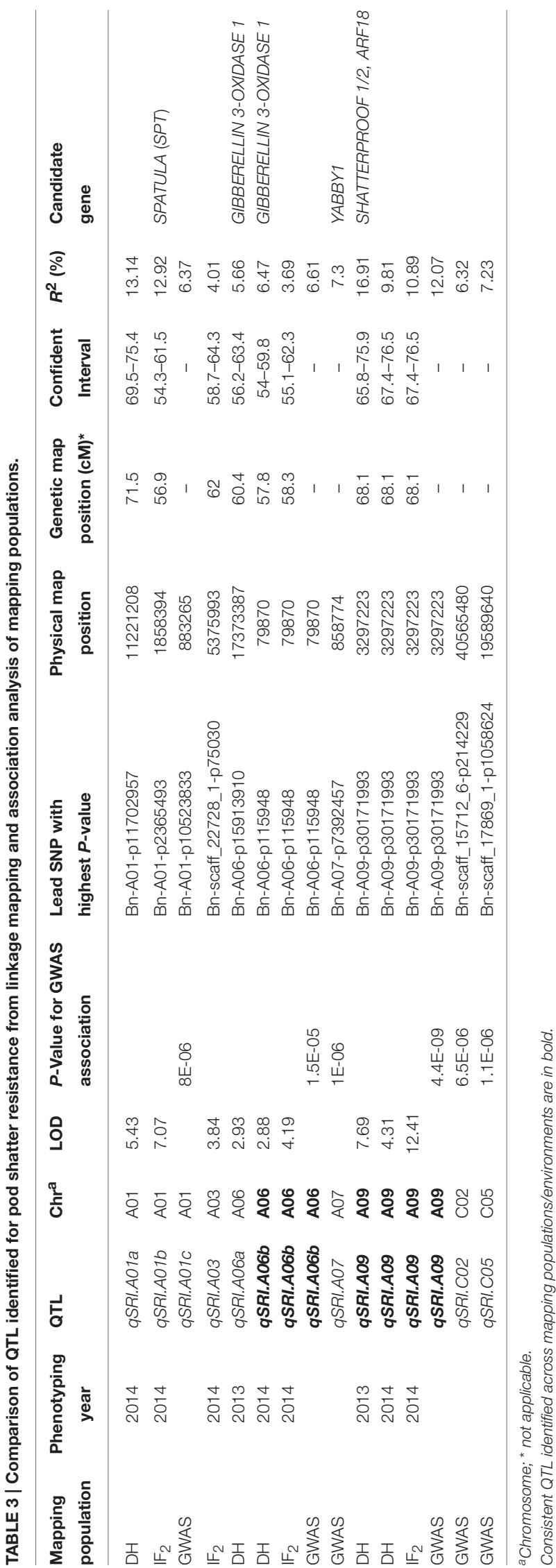

reported previously, suggesting that indeed QTL identified herein are relevant to international germplasm and rapeseed breeding programs.

In order to identify putative candidate genes involved in pod shatter resistance in the mapping populations (GWAS, DH, and $\mathrm{IF}_{2}$ ) investigated herein, we compared the physical map positions of SNP markers that showed significant associations in GWAS and mapping populations and known candidate genes involved in positively and negatively regulation of pod shatter such as FILAMENTOUS FLOWER, YABBY3, ASYMETERICAL LEAVES1/2, BREVIPEDICELLUS, SHATTERPROOF1/2, INDEHISCENT, ALCATRAZ, FRUITFUL, APETELA2, NAC SECONDARY WALL THICKENING PROMOTING FACTOR1, SECONDARY WALL-ASSOCIATED NAC DOMAIN PROTEIN1, DEHISCENCE ZONE POLYGALACTURONASE1, SPATULA, and PIN3 (reviewed in Dong and Wang, 2015) (Supplementary Table 4) on the sequenced B. napus genome. Among these significant SNPs underlying genetic variation for pod shatter resistance (Table 3), Bn-A01-p2365493 at the qSRI.A01b (A01) was mapped to a candidate gene SPATULA; Bn-A06-p15913910 and Bn-A06-p115948 corresponding with qSRI.A06a (A06) and the $q S R I . A 06 b$ (A06) were all mapped to candidate genes GIBBERELLIN 3-OXIDASE 1; Bn-A07-p7392457 at the qSRI.A07 (A07) was mapped to a candidate gene YABBY1. Except that, Bn-A09-p30171993 at the qSRI.A09 (A09) was mapped two homologous regions on $\mathrm{A} 09$ and $\mathrm{C} 08$ which is within $11 \mathrm{~kb}$ from the ARF18 gene controlling seed weight and pod length in B. napus (Liu et al., 2015). Both copies of ARF18 in $B$. napus; BnaA.ARF18.a and BnaA.ARF18.c were also located on the physical positions of chromosomes A09 and C08, respectively (Supplementary Table 4, Figure 4). PCR marker, Shp-100925 associated with BnSHP-1 locus on chromosome A09 was also mapped in the vicinity of qSRI.A09 and ARF18 (Figure 4).

\section{Allelic Diversity at Significant QTL Associated with Pod Shatter Resistance}

Based on the PSRI ranking of 143 accessions used for GWAS, 18 elite cultivars having PSRI $\geq 0.28$ were selected and their allele diversity was investigated at QTL qSRI.A01, qSRI.A06b, qSRI.A07, qSRI.A09, qSRI.C02, and qSRI.C05 that showed significant associations with lead SNP markers (Tables 3, 4). These 18 accessions were originated from 5 provinces of China (Supplementary Table 1), representing the main rapeseed production area of the Yangtze River eco-region. About onehalf of the resistant accessions, including the top five with PSRI $\geq 0.44$ (Table 4), all originated from Hubei province in the middle Yangtze River eco-region, shared the "CC" SNP allele at Bn-A09-p30171993 locus. Generally, the resistant accessions possess multiple favorable alleles suggesting the potential for recombining them in a breeding design to improve resistance to pod shatter in rapeseed breeding programs. For example, the most resistant genotype, Zhongshuang2 might be further improved through complementary recombination with the favorable alleles (CC) of Bn-A09-p30171993 from other resistant accessions identified in this study (Table 4). In 
addition, combining favorable alleles among other accessions would also improve pod shatter resistance within a breeding program.

\section{DISCUSSION}

\section{Genetic Variation for Pod Shatter Resistance in Rapeseed}

In this study, we determined the extent of genetic variation for pod shatter resistance in bi-parental $\mathrm{DH}$ and $\mathrm{IF}_{2}$ populations, and GWAS diversity panel comprising 143 accessions representing released Chinese cultivars/advanced breeding lines. We identified seven accessions with PSRI $\geq 0.4$ across years which exhibited improved levels of PSRI such as Zhongshuang2, OG3151, and Zhen2609, compared to standard check cultivars and would provide valuable resources for genetic improvement of pod shatter resistance in rapeseed improvement programs. However, we could not benchmark the level of resistance to pod shatter among accessions utilized in this study and previous ones (Wen et al., 2008; Pu et al., 2013, Raman et al., 2014), due to different assessment methods, germplasm, and growing conditions. Previous studies showed that there is a limited natural variation for pod shatter resistance in rapeseed (Wen et al., 2008; Raman et al., 2014), which has contributed to the lack of significant genetic improvement for this trait in breeding programs. It is possible that improved pod shatter resistance characterized herein may have been derived from pod shatter resistant sources of $B$. rapa, as they have been extensively used for introgression of novel alleles for traits of interest as well as to expand genetic base of rapeseed germplasm especially in China (Qian et al., 2005; Zou et al., 2010). Sources of pod shatter resistance are well documented in $B$. rapa gene pool and have been exploited in breeding programs (Kadkol et al., 1985, 1986; Mongkolporn et al., 2003; Hossain et al., 2011; Raman et al., 2014).

A laboratory based method (RIT) proved to be robust in determining the extent of pod-shatter resistance across several experiments. Further research efforts are needed to validate RIT for pod shatter resistance with pendulum test and field based methods such as delayed harvest across rapeseed growing regions.

\section{Genetic Basis of Phenotypic Variation in Pod Shatter Resistance}

We utilized both classical QTL and GWAS approaches to detect genomic regions associated with pod shatter resistance (Table 3). Both these approaches have their own advantages and disadvantages in QTL detection. For example, classical linkage analysis has strong statistical power and proven to be effective in detecting QTL, but only capture the recombination events in two parents used in constructing bi-parental $\mathrm{DH}$ /intercross populations. GWA simultaneously detects multiple alleles at the same locus, due to the accumulation of historical recombination events during systematic selection in breeding and resolves QTL based on LD particularly in species such as rapeseed where LD decays rapidly (Flint-Garcia et al., 2003; Buckler et al.,
2009; Gajardo et al., 2015). The combined application of both approaches; QTL and GWAS not only improve the efficiency of QTL detection, but also facilitate the identification of reliable and stable QTL and novel alleles across a wide range of germplasm (Krill et al., 2010; Raman et al., 2014, 2016).

In this study, we identified six QTL associated with pod shatter resistance which accounted for up to $50 \%$ the phenotypic variation in PSRI in $\mathrm{DH}$ and $\mathrm{IF}_{2}$ mapping populations. Previously, several QTL associated with pod shatter resistance were identified in a $\mathrm{DH}$ mapping populations derived from ZY72360/R1, H155/Qva, and BLN2762/Surpass400, and in diverse panel of accessions of $B$. napus, originated from Australia, China, and Europe (Hu et al., 2012; Wen et al., 2013; Raman et al., 2014). For example, Wen et al. (2013) identified 13 QTL for pod shatter resistance on the chromosomes A01, A04, A07, $\mathrm{A} 08, \mathrm{C} 05$, and C08; however only three of them were consistent at both locations. Recently, Raman et al. (2014) identified 12 QTL associated with pod shatter resistance in a $\mathrm{DH}$ population from BLN2762/Surpass400 on chromosomes A03, A07, A09, C03, C04, C06, and C08 using DArTseq markers. In silico mapping analysis of Illumina SNP markers showed that some of the QTL identified in this study are similar as reported previously (Raman et al., 2014) such as on A01, A03, and A09. Two QTL qSRI.A06 (A06) and qSRI.A09 (A09) were detected repeatedly across $\mathrm{DH}$ and GWAS populations and phenotypic environments, implicating their involvement in pod shatter resistance in rapeseed cultivars of Chinese origin. This suggests that there were at least two genes involved in resistance to pod shattering in $\mathrm{DH}$ and $\mathrm{IF}_{2}$ populations derived from R1. In a previous study (Hu et al., 2012), one major quantitative trait locus psr1 on chromosome A09 accounting $47 \%$ of phenotypic variation in pod shatter resistance was identified in an $\mathrm{F}_{2}$ population derived from ZY72360/R1. Comparative analysis of the A09 locus in the linkage maps of BLN2762/Surpass400 (Raman et al., 2014) and R1/R2 (this study) with B. napus physical map, showed an inversion event of the $400 \mathrm{~kb}$ QTL interval qSRI.A09/Qrps.wwai-A09. This result is partly consistent with the previous comparative genomic studies showing rearrangements in the A subgenome of B. napus (Xu et al., 2010; Li et al., 2014).

The present study showed that the PCR marker, Shp-100925 associated with BnSHP-1 locus was mapped in the vicinity of qSRI.A09 and ARF18 (Figure 4). The role of auxin in pod dehiscence and other developmental processes has been documented in Arabidopsis (Okushima et al., 2005; Sorefan et al., 2009), B. juncea, and B. napus (Jaradat et al., 2014). For example, Sorefan et al. (2009) reported that a local auxin minimum is required for the formation of valve margin separation layer for seed dehiscence which is controlled by IND gene. ARF18 gene also regulates cell growth in the pod wall via auxin-response pathway in B. napus and simultaneously affects seed weight and pod length in an $F_{2}$ population derived from the ZY72360/R1 (Liu et al., 2015). In a recent study, auxin biosynthesis, transport, and signaling was shown to be repressed in B. juncea (less prone to shattering) compared to $B$. napus (more prone to pod shattering) genotypes (Jaradat et al., 2014). These studies suggest that that the auxin minimum may be responsible for pod shatter trait in the mapping populations investigated here. 
Lir et al.

Multigenic Control of Pod Shattering Resistance

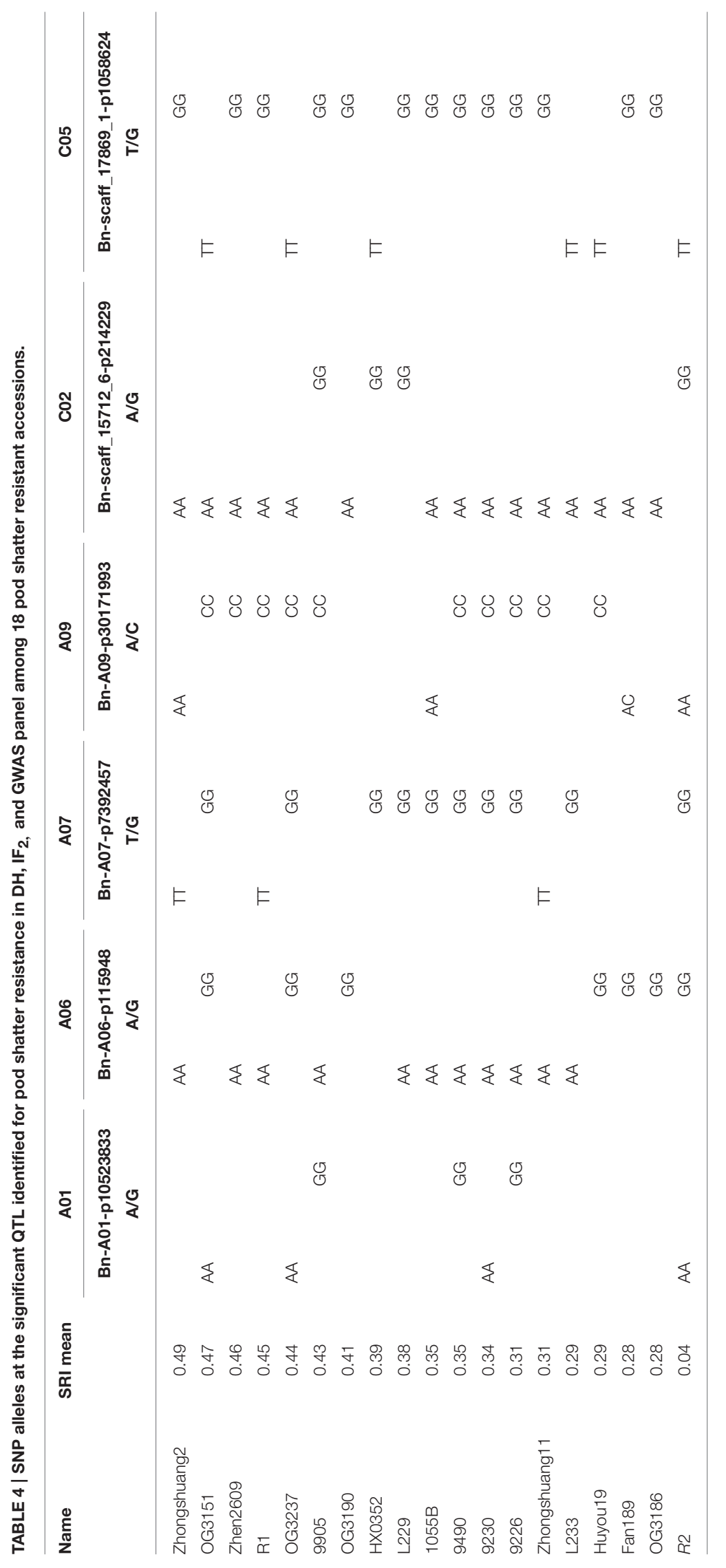

Frontiers in Plant Science | www.frontiersin.org

July 2016 | Volume 7 | Article 1058 


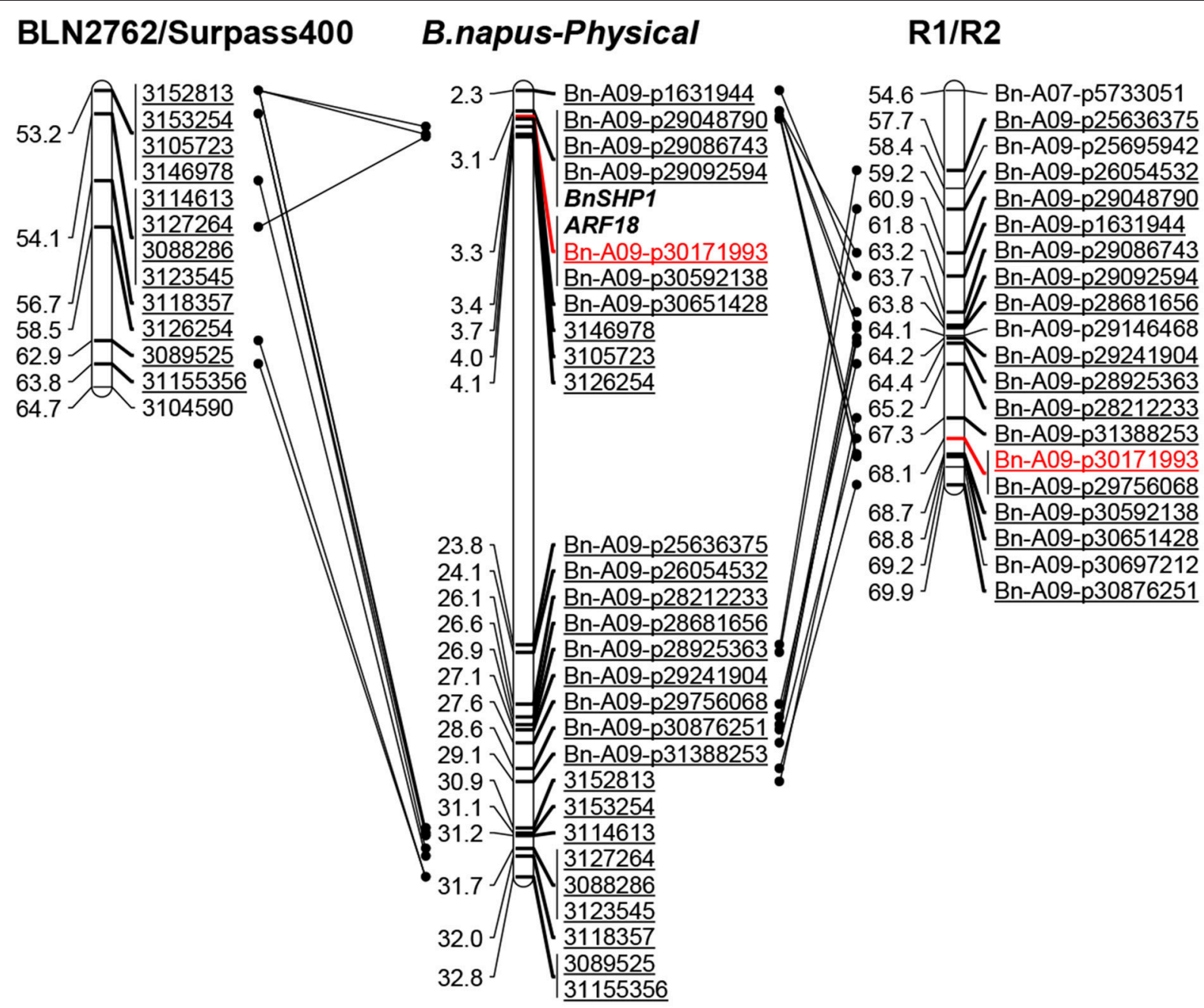

FIGURE 4 | Comparative analysis of qSRI.A09 on chromosome A09 for pod shatter resistance in the RR-DH and previously mapped populations. Left: the DArTseq markers in the order of the genetic map (cM) for B. napus based on a previous study (Raman et al., 2014). Middle: the markers in the order of the physical map $(\mathrm{Kb})$ for B. napus (Darmor-bzh). Physical map distances are given in fraction (1/1,000,000th) of the actual coordinates of the B. napus genome. The markers in red are the most associated marker for pod shattering resistance. Right: the markers in the order of the genetic map (cM) for R1/R2 (RR-DH) population used in the current study. The marker in red showed highly significant association with pod shatter resistance at qSRI.A09.

Further studies are required to establish the role of auxins in genetic variation for pod shattering resistance in diverse $B$. napus accessions.

In addition to qSRI.A09/Qrps.wwai-A09/psr1 locus on A09 (Hu et al., 2012; Raman et al., 2014, this study), other QTL qSRI.A01 (A01), qSRI.A03 (A03), qSRI.A07 (A07), qSRI.C02 (C02), and qSRI.C05 (C05) also account genetic variation for pod shatter resistance derived from R1, a pod shatter resistant Chinese cultivar. Arabidopsis genes underlying the significant QTL such as SPATULA and GIBBERELLIN 3-OXIDASE 1 (Table 3) are likely candidate genes for pod shatter resistance in mapping populations. A basic-helix-loop-helix transcription factor, SPATULA is implicated in dehiscence zone in Arabidopsis and regulated by $A R F$ (Heisler et al., 2001), suggesting its role in auxin-mediated dehiscence zone formation implicated in pod shatter. GA3ox1 encodes a Gibberellin 3-oxidase, which is a direct and necessary target of IND gene (Arnaud et al., 2010). Identification of closely linked markers and the genomic location of QTL on chromosomes A01, A06, A07 and A09 with respect to a reference genome of $B$. napus and the described genes involved in pod shatter resistance of Arabidopsis could also pave the way for map-based cloning of those QTL and unravel the molecular architecture of pod shatter resistance genes in natural germplasm of $B$. napus.

\section{CONCLUSION}

Both GWAS and linkage analyses enabled to untangle multiple quantitative trait loci associated with pod shatter resistance in Chinese germplasm of rapeseed. Identification of the improved sources for pod shatter resistance, and understanding the genetic 
basis underlying genetic variation in pod shattering resistance in rapeseed germplasm will provide insights into the complex architecture and evolution of this trait which has been subjected to artificial selection since its domestication. SNP markers flanking QTL regions would provide an efficient method for selection of alleles associated with pod shatter resistance in rapeseed breeding programs.

\section{AUTHOR CONTRIBUTIONS}

$\mathrm{JL}$ and $\mathrm{QH}$ conceived and designed the study. JW and HW conducted the $\mathrm{DH}$ and $\mathrm{IF}_{2}$ population experiments; JL and WW carried out the association population experiments; JW and $\mathrm{HW}$ analyzed the $\mathrm{DH}$ and $\mathrm{IF}_{2}$ data; $\mathrm{JL}$ and $\mathrm{WW}$ analyzed the association data; $\mathrm{DM}$ and $\mathrm{JW}$ produced the $\mathrm{DH}$ and $\mathrm{IF}_{2}$ populations; RZ, HC, and JY did the phenotype assessment; JL, JW, and HR interpreted the data and prepared the manuscript; HR performed comparative and in silico analysis; QH supervised the whole study; all authors reviewed and edited the manuscript.

\section{REFERENCES}

Arnaud, N., Girin, T., Sorefan, K., Fuentes, S., Wood, T. A., Lawrenson, T., et al. (2010). Gibberellins control fruit patterning in Arabidopsis thaliana. Genes Dev. 24, 2127-2132. doi: 10.1101/gad.593410

Bancroft, I., Morgan, C., Fraser, F., Higgins, J., Wells, R., Clissold, L., et al. (2011). Dissecting the genome of the polyploid crop oilseed rape by transcriptome sequencing. Nat. Biotechnol. 29, 762-766. doi: 10.1038/nb t.1926

Bayer, P., Ruperao, P., Mason, A., Stiller, J., Chan, C. K., Hayashi, S., et al. (2015). High-resolution skim genotyping by sequencing reveals the distribution of crossovers and gene conversions in Cicer arietinum and Brassica napus. Theor. Appl. Genet. 128, 1039-1047. doi: 10.1007/s00122-015-2488-y

Benjamini, Y., and Hochberg, Y. (1995). Controlling the false discovery rate - a practical and powerful approach to multiple testing. J. R. Stat. Soc. B-Methodol. 57, 289-300.

Bradbury, P. J., Zhang, Z., Kroon, D. E., Casstevens, T. M., Ramdoss, Y., and Buckler, E. S. (2007). TASSEL: software for association mapping of complex traits in diverse samples. Bioinformatics 23, 2633-2635. doi: 10.1093/bioinformatics/btm308

Brown, A. F., Yousef, G. G., Chebrolu, K. K., Byrd, R. W., Everhart, K. W., Thomas, A., et al. (2014). High-density single nucleotide polymorphism (SNP) array mapping in Brassica oleracea: identification of QTL associated with carotenoid variation in broccoli florets. Theor. Appl. Genet. 127, 2051-2064. doi: 10.1007/s00122-014-2360-5

Buckler, E. S., Holland, J. B., Bradbury, P. J., Acharya, C. B., Brown, P. J., Browne, C., et al. (2009). The genetic architecture of maize flowering time. Science 325, 714-718. doi: 10.1126/science.1174276

Chalhoub, B., Denoeud, F., Liu, S., Parkin, I. A. P., Tang, H., Wang, X., et al. (2014). Early allopolyploid evolution in the post-Neolithic Brassica napus oilseed genome. Science 345, 950-953. doi: 10.1126/science.12 53435

Churchill, G. A., and Diverge, R. W. (1994). Empirical threshold values for quantitative trait mapping. Genetics 138, 963-971.

Dabney, A., and Storey, J. D. (2004). Q-value estimation for false discovery rate control. Medicine 344, 539-548.

Dong, Y., and Wang, Y. Z. (2015). Seed shattering: from models to crops. Front. Plant Sci. 6:476. doi: 10.3389/fpls.2015.00476

Dong, Y., Yang, X., Liu, J., Wang, B. H., Liu, B. L., and Wang, Y. Z. (2014). Pod dehiscence resistance associated with domestication is mediated by a NAC gene in soybean. Nat.Commun. 5, 3352. doi: 10.1038/ncomms 4352

\section{ACKNOWLEDGMENT}

We would like to thank the reviewers for their valuable suggestions and comments on this manuscript. The National Key Basic Research Program (2011CB1093), the Natural Science Foundation of China (31471535), the Science and Technology Innovation Project of Chinese Academy of Agricultural Sciences (Group No. 118), the Earmarked Fund for China Agriculture Research System (CARS-13), the Hubei Agricultural Science and Technology Innovation Center (201620000001048) and Australian Grains Research and Development Corporation (DAN00208) supported this work.

\section{SUPPLEMENTARY MATERIAL}

The Supplementary Material for this article can be found online at: http://journal.frontiersin.org/article/10.3389/fpls.2016. 01058

Evanno, G., Regnaut, S., and Goudet, J. (2005). Detecting the number of clusters of individuals using the software STRUCTURE: a simulation study. Mol. Ecol. 14, 2611-2620. doi: 10.1111/j.1365-294x.2005.02553.x

Ferrándiz, C., Liljegren, S. J., and Yanofsky, M. F. (2000). Negative regulation of the SHATTERPROOF genes by FRUITFULL during Arabidopsis fruit development. Science 289, 436-438. doi: 10.1126/science.289.5478.436

Flint-Garcia, S. A., Thornsberry, J. M., and Buckler, E. S. (2003). Structure of linkage disequilibrium in plants. Annu. Rev. Plant Biol. 54, 357-374. doi: 10.1146/annurev.arplant.54.031902.134907

Fu, Y., Wei, D. Y., Dong, H. L., He, Y. J., Cui, Y. X., Mei, J. Q., et al. (2015). Comparative quantitative trait loci for silique length and seed weight in Brassica napus. Sci. Rep. 5:14407. doi: 10.1038/srep14407

Funatsuki, H., Suzuki, M., Hirose, A., Inaba, H., Yamada, T., Hajika, M., et al. (2014). Molecular basis of a shattering resistance boosting global dissemination of soybean. Proc. Natl. Acad. Sci. U.S.A. 111, 17797-17802. doi: 10.1073/pnas.1417282111

Gabriel, S. B., Schaffner, S. F., Nguyen, H., Moore, J. M., Roy, J., Blumenstiel, B., et al. (2002). The structure of haplotype blocks in the human genome. Science 296, 2225-2229. doi: 10.1126/science.1069424

Gajardo, H., Wittkop, B., Soto-Cerda, B., Higgins, E., Parkin, I. P., Snowdon, R., et al. (2015). Association mapping of seed quality traits in Brassica napus L. using GWAS and candidate QTL approaches. Mol. Breed. 35, 1-19. doi: $10.1007 / \mathrm{s} 11032-015-0340-3$

Gao, M., and Zhu, H. (2013). Fine mapping of a major quantitative trait locus that regulates pod shattering in soybean. Mol. Breed. 32, 485-491. doi: 10.1007/s11032-013-9868-2

Girin, T., Stephenson, P., Goldsack, C. M., Kempin, S. A., Perez, A., Pires, N., et al. (2010). Brassicaceae INDEHISCENT genes specify valve margin cell fate and repress replum formation. Plant J. 63, 329-338. doi: 10.1111/j.1365313X.2010.04244.X

Heisler, M. G., Atkinson, A., Bylstra, Y. H., Walsh, R., and Smyth, D. R. (2001). SPATULA, a gene that controls development of carpel margin tissues in Arabidopsis, encodes a bHLH protein. Development 128, 1089-1098.

Hossain, S., Kadkol, G., Raman, R., Salisbury, P., and Raman, H. (2011). "Breeding Brassica napus for shatter resistance," in Plant Breeding, ed I. Y. Abdurakhmonov. Available online at: http://www.intechopen.com/articles/ show/title/breeding-brassica-napus-for-shatter-resistance

Hu, Z. Y., Hua, W., Huang, S. M., Yang, H. L., Zhan, G. M., Wang, X. F., et al. (2012). Discovery of pod shatter-resistant associated SNPs by deep sequencing of a representative library followed by bulk segregant analysis in rapeseed. PLoS ONE 7:e34253. doi: 10.1371/journal.pone.0034253 
Hua, J. P., Xing, Y. Z., Xu, C. G., Sun, X. L., Yu, S. B., and Zhang, Q. F. (2002). Genetic dissection of an elite rice hybrid revealed that heterozygotes are not always advantageous for performance. Genetics 162, 1885-1895.

Jakobsson, M., and Rosenberg, N. A. (2007). CLUMPP: a cluster matching and permutation program for dealing with label switching and multimodality in analysis of population structure. Bioinformatics 23, 1801-1806. doi: 10.1093/bioinformatics/btm233

Jaradat, M. R., Ruegger, M., Bowling, A., Butler, H., and Cutler, A. J. (2014). A comprehensive transcriptome analysis of silique development and dehiscence in Arabidopsis and Brassica integrating genotypic, interspecies and developmental comparisons. GM Crops Food 5, 302-320. doi: 10.4161/21645698.2014.947827

Kadkol, G. P., Halloran, G. M., and MacMillan, R. H. (1985). Evaluation of Brassica genotypes for resistance to shatter. II. Variation in siliqua strength within and between accessions. Euphytica 34, 915-924. doi: 10.1007/BF00035431

Kadkol, G. P., Halloran, G. M., and MacMillan, R. H. (1986). Inheritance of siliqua strength in Brassica campestris L. I. Studies of $\mathrm{F}_{2}$ and backcross populations. Can. J. Genet. Cytol. 28, 365-373. doi: 10.1139/g86-054

Kadkol, G. P., MacMillan, R. H., Burrow, R. P., and Halloran, G. M. (1984). Evaluation of Brassica genotypes for resistance to shatter. I. Development of a laboratory test. Euphytica 33, 63-73. doi: 10.1007/BF00022751

Konishi, S., Izawa, T., Lin, S. Y., Ebana, K., Fukuta, Y., Sasaki, T., et al. (2006). An SNP caused loss of seed shattering during rice domestication. Science 312, 1392-1396. doi: 10.1126/science. 1126410

Kosambi, D. D. (1944). The estimation of map distances from recombination values. Ann. Eugen. 12, 172-175. doi: 10.1111/j.1469-1809.1943.tb02321.x

Krill, A. M., Kirst, M., Kochian, L. V., Buckler, E. S., and Hoekenga, O. A. (2010). Association and linkage analysis of aluminum tolerance genes in maize. PLoS ONE 5:e9958. doi: 10.1371/journal.pone.0009958

Lewis, M. W., Leslie, M. E., and Liljegren, S. J. (2006). Plant separation: 50 ways to leave your mother. Curr. Opin. Plant Biol. 9, 59-65. doi: 10.1016/j.pbi.2005.11.009

Li, C., Zhou, A., and Sang, T. (2006). Rice domestication by reducing shattering. Science 311, 1936-1939. doi: 10.1126/science.1123604

Li, N., Shi, J., Wang, X., Liu, G., and Wang, H. Z. (2014). A combined linkage and regional association mapping validation and fine mapping of two major pleiotropic QTLs for seed weight and silique length in rapeseed (Brassica napus L.). BMC Plant Biol. 14:114. doi: 10.1186/1471-2229-14-114

Liljegren, S. J., Ditta, G. S., Eshed, Y., Savidge, B., Bowman, J., and Yanofsky, M. F. (2000). SHATTERPROOF MADS-box genes control seed dispersal in Arabidopsis. Nature 404, 766-770. doi: 10.1038/35008089

Liu, J., Hua, W., Hu, Z. Y., Yang, H. L., Zhang, L., Li, R. J., et al. (2015). Natural variation in ARF18 gene simultaneously affects seed weight and silique length in polyploid rapeseed. Proc. Natl. Acad. Sci. U.S.A. 112, E5123-E5132. doi: $10.1073 /$ pnas. 1502160112

Liu, J., Mei, D. S., Li, Y. C., Cui, J. C., Wang, H., Peng, P. F., et al. (2013). Combining ability and breeding potential of rapeseed elite lines for pod shatter resistance. J. Integr. Agric. 12, 552-555. doi: 10.1016/s2095-3119(13)60256-7

Liu, L., Qu, C., Wittkop, B., Yi, B., Xiao, Y., He, Y. et al. (2013). A High-Density SNP Map for Accurate Mapping of Seed Fibre QTL in Brassica napus L. PLoS ONE 8:e83052. doi: 10.1371/journal.pone.0083052

Liu, S., Liu, Y., Yang, X., Tong, C., Edwards, D., Parkin, I. A. P., et al. (2014). The Brassica oleracea genome reveals the asymmetrical evolution of polyploid genomes. Nat. Commun. 5, 3930. doi: 10.1038/ncomms4930

Liu, Z. S. (1994). Genetic and breeding studies on distant hybridization in rapeseed. II. Cross compatibility between Brassica napus and B. juncea and their F1s. Oil Crops China 16, 1-5.

Loiselle, B. A., Sork, V. L., Nason, J., and Graham, C. (1995). Spatial geneticstructure of a tropical understory shrub, Psychotria officinalis (Rubiaceae). Am. J. Bot. 82, 1420-1425. doi: 10.2307/2445869

Mauricio, R. (2001). Mapping quantitative trait loci in plants: uses and caveats for evolutionary biology. Nat. Rev. Genet. 2, 370-381. doi: 10.1038/35072085

Mongkolporn, O., Kadkol, G. P., Pang, E. C. K., and Taylor, P. W. J. (2003). Identification of RAPD markers linked to recessive genes conferring siliqua shatter resistance in Brassica rapa. Plant Breed. 122, 479-484. doi: 10.1046/j.0179-9541.2003.00910.x

Morgan, C. L., Bruce, D. M., Child, R., Ladbrooke, Z. L., and Arthur, A. E. (1998). Genetic variation for pod shatter resistance among lines of oilseed rape developed from synthetic B-Napus. Field Crops Res. 58. 153-165. doi: 10.1016/S0378-4290(98)00099-9

Morgan, C. L., Ladbrooke, Z. L., Bruce, D. M., Child, R., and Arthur, A., E. (2000). Breeding oilseed rape for pod shattering resistance. J. Agric. Sci. 135, 347-359. doi: 10.1017/s0021859699008424

Okushima, Y., Overvoorde, P. J., Arima, K., Alonso, J. M., Chan, A., Chang, C., et al. (2005). Functional genomic analysis of the AUXIN RESPONSE FACTOR gene family members in Arabidopsis thaliana: unique and overlapping functions of ARF7 and ARF19. Plant Cell 17, 444-463. doi: $10.1105 /$ tpc. 104.028316

Østergaard, L. (2009). Don't 'leaf' now. The making of a fruit. Curr. Opin. Plant Biol. 12, 36-41. doi: 10.1016/j.pbi.2008.09.011

Parkin, I. A. P., Koh, C., Tang, H., Robinson, S., Kagale, S., Clarke, W., et al. (2014). Transcriptome and methylome profiling reveals relics of genome dominance in the mesopolyploid Brassica oleracea. Genome Biol. 15:R77. doi: 10.1186/gb2014-15-6-r77

Peng, P., Li, Y. C., Mei, D., Liu, D., Fu, L., Wang, H., et al. (2013). Optimization and experiment of assessment method for pod shatter resistance in Brassica napus L. Trans. Chin. Soc. Agric. Eng. 29, 19-25. doi: 10.3969/j.issn.10026819.2013.21.003

Price, J. S., Hobson, R. N., Neale, M. A., and Bruce, D. M. (1996). Seed losses in commercial harvesting of oilseed rape. J. Agric. Eng. Res. 65, 183-191. doi: 10.1006/jaer.1996.0091

Pritchard, J. K., Stephens, M., and Donnelly, P. (2000). Inference of population structure using multilocus genotype data. Genetics 155, 945-959.

Pu, H. M., Long, W. H., Gao, J. Q., and Hu, M. L. (2013). Silique shatter resistance and correlation analysis in Brassica napus. Oil Crops China 35, 469-475. doi: 10.7505/j.issn.1007-9084.2013.05.002

Qian, W., Chen, X., Fu, D., Zou, J., and Meng, J. (2005). Intersubgenomic heterosis in seed yield potential observed in a new type of Brassica napus introgressed with partial Brassica rapa genome. Theor. Appl. Genet. 110, 1187-1194. doi: 10.1007/s00122-005-1932-9

Rajani, S., and Sundaresan, V. (2001). The Arabidopsis myc/bHLH gene ALCATRAZ enables cell separation in fruit dehiscence. Curr. Biol. 11, 1914-1922. doi: 10.1016/S0960-9822(01)00593-0

Raman, H., Raman, R., Coombes, N., Song, J., Prangnell, R., Bandaranayake, C., et al. (2016). Genome-wide association analyses reveal complex genetic architecture underlying natural variation for flowering time in canola. Plant Cell Environ. 39, 1228-1239. doi: 10.1111/pce.12644

Raman, H., Raman, R., Kilian, A., Detering, F., Carling, J., Coombes, N., et al. (2014). Genome-wide delineation of natural variation for pod shatter resistance in Brassica napus. PLoS ONE 9:e101673. doi: 10.1371/journal.pone.01 01673

Saghai-Maroof, M. A., Soliman, K. M., Jorgensen, R. A., and Allard, R. W. (1984). Ribosomal DNA spacer-length polymorphisms in barley: mendelian inheritance, chromosomal location, and population-dynamics. Proc. Natl. Acad. Sci. U.S.A. 81, 8014-8018. doi: 10.1073/pnas.81.24.8014

SAS Institute Inc. (1999). SAS Online Doc@, version 8.1. Cary, NC.

Schiessl, S., Samans, B., Hüttel, B., Reinhardt, R., and Snowdon, R. J. (2014). Capturing sequence variation among flowering-time regulatory gene homologues in the allopolyploid crop species Brassica napus. Front. Plant Sci. 5:404. doi: 10.3389/fpls.2014.00404

Sorefan, K., Girin, T., Liljegren, S. J., Ljung, K., Robles, P., Galvan-Ampudia, C. S., et al. (2009). A regulated auxin minimum is required for seed dispersal in Arabidopsis. Nature 459, 583-586. doi: 10.1038/nature07875

Stam, P. (1993). Construction of integrated genetic linkage maps by means of a new computer package: joinmap. Plant J. 3, 739-744. doi: 10.1111/j.1365313X.1993.00739.x

Sun, G., Zhu, C. M., Kramer, H. S., Yang, S., Song, W., Piepho, H. P. et al. (2010). Variation explained in mixed-model association mapping. Heredity 105, 333-340. doi: 10.1038/hdy.2010.11

Trick, M., Long, Y., Meng, J., and Bancroft, I. (2009). Single nucleotide polymorphism (SNP) discovery in the polyploid Brassica napus using Solexa transcriptome sequencing. Plant Biotechnol. J. 7, 334-346. doi: 10.1111/j.14677652.2008.00396.x

Wang, J. K., Li, H. H., Zhang, L. Y., Li, C. H., and Meng, L. (2014). Users' Manual of QTL IciMapping V4.0. Beijing. Available online at: http://www.isbreeding.net/ software/?type=detail\&id=14 
Wang, S., Basten, C. J., and Zeng, Z. B. (2007). Windows QTL Cartographer 2.5. Raleigh, NC: Department of Statistics, North Carolina State University. Available online at: http://statgen.ncsu.edu/qtlcart/WQTLCart.htm

Wang, X., Wang, H., Wang, J., Sun, R., Wu, J., Liu, S. Y., et al. (2011). The genome of the mesopolyploid crop species Brassica rapa. Nat. Genet. 43, 1035-1039. doi: 10.1038/ng.919

Wang, X., Yu, K., Li, H., Peng, Q., Chen, F., Zhang, W., et al. (2015). High-density SNP map construction and QTL identification for the apetalous character in Brassica napus L. Front. Plant Sci. 6:1164. doi: 10.3389/fpls.2015.01164

Wei, W. H., Li, Y. C., Wang, L. J., Liu, S. Y., Yan, X. H., Mei, D. S., et al. (2010). Development of a novel Sinapis arvensis disomic addition line in Brassica napus containing the restorer gene for Nsa CMS and improved resistance to Sclerotinia sclerotiorum and pod shattering. Theor. Appl. Genet. 120, 1089-1097. doi: 10.1007/s00122-009-1236-6

Wen, Y. C., Fu, T., Tu, J., Ma, C., Shen, J., Zhang, S., et al. (2008). Screening and analysis of resistance to silique shattering in rape (Brassica napus L.). Acta Agron. Sin. 34, 163-166. doi: 10.3724/sp.j.1006.2008.00163

Wen, Y. C., Zhang, S. F., Yi, B., Wen, J., Wang, J. P., et al. (2013). Identification of QTLs involved in pod-shatter resistance in Brassica napus L. Crop Pasture Sci. 63, 1082-1089. doi: 10.1071/CP12318

Xu, J., Qian, X., Wang, X., Li, R., Cheng, X., Yang, Y., et al. (2010). Construction of an integrated genetic linkage map for the A genome of Brassica napus using SSR markers derived from sequenced BACs in B. rapa. BMC Genomics 11:594. doi: 10.1186/1471-2164-11-594

Yoon, J., Cho, L. H., Kim, S. L., Choi, H., Koh, H. J., and An, G. (2014). The BEL1- type homeobox gene SH5 induces seed shattering by enhancing abscission- zone development and inhibiting lignin biosynthesis. Plant J. 79, 717-728. doi: 10.1111/tpj.12581

Yu, J. M., Pressoir, G., Briggs, W. H., Bi, I. V., Yamasaki, M., Doebley, J. F., et al. (2006). A unified mixed-model method for association mapping that accounts for multiple levels of relatedness. Nat. Genet. 38, 203-208. doi: 10.1038/ng1702

Zhang, Z., Ersoz, E., Lai, C. Q., Todhunter, R. J., Tiwari, H. K., Gore, M. A., et al. (2010). Mixed linear model approach adapted for genome-wide association studies. Nat. Genet. 42, 355-360. doi: 10.1038/ng.546

Zhou, Y., Lu, D., Li, C., Luo, J., Zhu, B. F., Zhu, J., et al. (2012). Genetic control of seed shattering in rice by the APETALA2 transcription factor shattering abortion1. Plant Cell 24, 1034-1048. doi: 10.1105/tpc.111.094383

Zou, J., Zhu, J., Huang, S., Tian, E., Xiao, Y., Fu, D., et al. (2010). Broadening the avenue of intersubgenomic heterosis in oilseed Brassica. Theor. Appl. Genet. 120, 283-290. doi: 10.1007/s00122-009-1201-4

Conflict of Interest Statement: The authors declare that the research was conducted in the absence of any commercial or financial relationships that could be construed as a potential conflict of interest.

Copyright (C) 2016 Liu, Wang, Wang, Wang, Zhou, Mei, Cheng, Yang, Raman and $\mathrm{Hu}$. This is an open-access article distributed under the terms of the Creative Commons Attribution License (CC BY). The use, distribution or reproduction in other forums is permitted, provided the original author(s) or licensor are credited and that the original publication in this journal is cited, in accordance with accepted academic practice. No use, distribution or reproduction is permitted which does not comply with these terms. 